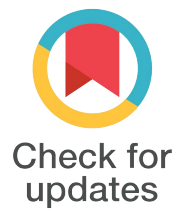

DOI: $10.21859 / \mathrm{ijcp}-03031$

\section{Cardiac Resynchronization Therapy With or Without Defibrillation}

\author{
Mohammad Ali Akbarzadeh ${ }^{1,2,}{ }^{,}$, Ayoub Salehi ${ }^{1,2}$ \\ ${ }^{1}$ Cardiovascular Research Center, Shahid Beheshti University of Medical \\ Sciences, Tehran, Iran \\ ${ }^{2}$ Department of Cardiology, School of Medicine, Beheshti University of \\ Medical Sciences, Tehran, Iran
}

*Corresponding author: Mohammad Ali Akbarzadeh, Cardiovascular Research

Center, Shahid Beheshti University of Medical Sciences, Tehran, Iran. E-mail: akbarzadehali@yahoo.com

\author{
Submitted: $10-06-2018$ \\ Accepted: 23-06-2018 \\ Keywords: \\ Cardiac Resynchronization \\ Therapy \\ Implantable Cardioverter \\ Defibrillator \\ Cardiomyopathy \\ (c) 2018. International Journal of \\ Cardiovascular Practice.
}

Indications for cardiac resynchronization therapy (CRT) with defibrillation (CRT-D) versus pacing (CRT-P) was challenging in the early 2000s. There were many researches to and fro of CRT-D versus CRT-P implantation in patients with cardiomyopathy (CMP) and left bundle branch block pattern in electrocardiography. In 2012, ACC/AHA/HRS (American College of Cardiology Foundation/American Heart Association Task Force on Practice Guidelines and the Heart Rhythm Society) guidelines, recommendations for implantable cardioverter defibrillator (ICD), was completely apart to the indications of CRT[1]. In such guidelines, ICD indicated for most of patients with ischemic CMP and patients with non-ischemic CMP with high functional class. Therefore, ICD simultaneously indicated many patients benefitting from CRT. Therefore, the indications for CRT-P are very limited according to these guidelines [1]. The ESC guideline recommends implantation of CRT-P instead of CRT-D only in patients with short life expectancy such as the ones with advanced renal failure [2].

Although left ventricular ejection fraction (LVEF) is an excellent practical marker of ventricular arrhythmic events, however, only a small percentage of ICD recipients receive appropriate ICD therapy [3]. The predictors of appropriate ICD therapy markedly vary between the studies. Non-sustained ventricular tachycardia, abnormal sphericity index, male gender, high NYHA (New York Heart Association) functional class, and smoking were reported as predictors for ventricular arrhythmia in few studies, but still not approved as good markers to change the decision [4-6]. Recently, the benefit of ICD for patients with dilated CMP was doubted in a Danish trial. This trial demonstrated that ICD implantation did not have survival benefits for patients with symptomatic heart failure not caused by coronary artery disease [7]. Accordingly, a recent study showed that midwall fibrosis detected by magnetic resonance imaging (MRI) may be a good predictor for adverse outcomes including ventricular tachyarrhythmia and sudden arrhythmic death in the patients with non-ischemic CMP; hence, CRT-D may be superior to CRT-P in this subgroup of patients with non-ischemic CMP [8].

On the other hand, in many pacemaker-dependent patients, only RV pacing may cause CMP. Kiehl et al., showed that incidence of pacemaker-induced cardiomyopathy was about $12.3 \%$ in patients with complete heart block treated with pacemaker; hence, it may be necessary to upgrade their device to CRT [9]. According to the current AHA and ESC guidelines, CRT implantation or upgrading to CRT device is observed in patients with high ventricular pacing and 
LVEF of $>35 \%$ de nevo $[1,2]$. This may explain that why through the first decade of this millennium, there was a significant de nevo CRT implantation in Europe and the United States; however, recently, upgrading of the existing pacemakers and ICDs dedicated a larger amount of CRT implantation [10]. Khurshid et al., showed reversal of pacing induced cardiomyopathy in more than $70 \%$ of patients after upgrading their device to CRT [11]. Therefore, it seems that the mechanism of CMP may be reversible especially if managed soon. With improvement of LVEF, such patients have no indication of ICD, either.

While there are no high-quality randomized data, choosing the device for such patients should be done with caution. It is necessary to consider the risks of twolead implantation instead of only single LV lead placement, more infection risk due to prolonger procedure time, and also the cost estimation of the decision.

\section{REFERENCES}

1. Epstein AE, DiMarco JP, Ellenbogen KA, Estes NA, 3rd, Freedman RA, Gettes LS, et al. 2012 ACCF/AHA/HRS Focused Update Incorporated into the Accf/Aha/Hrs 2008 Guidelines for Device-Based Therapy of Cardiac Rhythm Abnormalities: a Report of the American College of Cardiology Foundation/American Heart Association Task Force on Practice Guidelines and the Heart Rhythm Society. Circulation. 2013;127(3):e283-352. doi: 10.1161/CIR.0b013e318276ce9b pmid: 23255456

2. Brignole $\mathrm{M}$, Auricchio A, Baron-Esquivias G, Bordachar P, Boriani G, Breithardt OA, et al. 2013 ESC Guidelines on Cardiac Pacing and Cardiac Resynchronization Therapy: the Task Force on Cardiac Pacing and Resynchronization Therapy of the European Society of Cardiology (Esc). Developed in Collaboration with the European Heart Rhythm Association (EHRA). Eur Heart J. 2013;34(29):2281-329. doi: 10.1093/eurheartj/eht150 pmid: 23801822

3. Santangeli P, Dello Russo A, Casella M, Pelargonio G, Di Biase
L, Natale A. Left Ventricular Ejection Fraction for the Risk Stratification of Sudden Cardiac Death: Friend or Foe? Intern Med J. 2011;41(1a):55-60. doi: 10.1111/j.14455994.2010.02371.x pmid: 21265961

4. Verma A, Sarak B, Kaplan AJ, Oosthuizen R, Beardsall M, Wulffhart Z, et al. Predictors of Appropriate Implantable Cardioverter Defibrillator (ICD) Therapy in Primary Prevention Patients with Ischemic and Nonischemic Cardiomyopathy. Pacing Clin Electrophysiol. 2010;33(3):320-9. doi: 10.1111/j.1540-8159.2009.02566.x pmid: 19796352

5. Gracieux J, Sanders GD, Pokorney SD, Lopes RD, Thomas K, Al-Khatib SM. Incidence and Predictors of Appropriate Therapies Delivered by the Implantable Cardioverter Defibrillator in Patients with Ischemic Cardiomyopathy: a Systematic Review. Int J Cardiol. 2014;177(3):990-4. doi: 10.1016/j.ijcard.2014.09.170 pmid: 25449512

6. Anvari S, Akbarzadeh MA, Bayat F, Namazi MH, Safi M. Left Ventricular Sphericity Index Analysis for the Prediction of Appropriate Implantable Cardioverter-Defibrillator Therapy. Pacing Clin Electrophysiol. 2018;41(9):1192-6. doi: 10.1111 /pace. 13420 pmid: 29931684

7. Kober L, Thune JJ, Nielsen JC, Haarbo J, Videbaek L, Korup E, et al. Defibrillator Implantation in Patients with Nonischemic Systolic Heart Failure. N Engl J Med. 2016;375(13):1221-30. doi: 10.1056/NEJMoa1608029 pmid: 27571011

8. Leyva F, Zegard A, Acquaye E, Gubran C, Taylor R, Foley PWX, et al. Outcomes of Cardiac Resynchronization Therapy with or without Defibrillation in Patients with Nonischemic Cardiomyopathy. J Am Coll Cardiol. 2017;70(10):1216-27. doi: 10.1016/j.jacc.2017.07.712 pmid: 28859784

9. Kiehl EL, Makki T, Kumar R, Gumber D, Kwon DH, Rickard JW, et al. Incidence and Predictors of Right Ventricular PacingInduced Cardiomyopathy in Patients with Complete Atrioventricular Block and Preserved Left Ventricular Systolic Function. Heart Rhythm. 2016;13(12):2272-8. doi: 10.1016/j.hrthm.2016.09.027 pmid: 27855853

10. Shetty AK, Rinaldi CA. Cardiac Resynchronization Therapy Upgrade: Verschlimmbesserung? USA: American Heart Association; 2017.

11. Khurshid S, Obeng-Gyimah E, Supple GE, Schaller R, Lin D, Owens AT, et al. Reversal of Pacing-Induced Cardiomyopathy Following Cardiac Resynchronization Therapy. JACC Clin Electrophysiol. 2018;4(2):168-77. doi: 10.1016/j.jacep.2017.10.002 pmid: 29749933 